\title{
Appendix D. Credit Data for Commonwealth Countries
}

\begin{tabular}{|c|c|c|c|c|}
\hline & $\begin{array}{l}\text { Strength of legal } \\
\text { rights index } \\
(0=\text { weak to } \\
10=\text { strong) }\end{array}$ & $\begin{array}{l}\text { Depth of credit } \\
\text { information } \\
\text { index }(0-6)^{18}\end{array}$ & 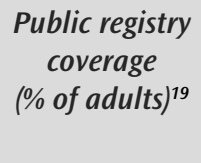 & $\begin{array}{c}\text { Private bureau } \\
\text { coverage } \\
(\% \text { of adults })^{20}\end{array}$ \\
\hline Antigua and Barbuda & 7 & 0 & 0 & 0 \\
\hline Australia & 9 & 5 & 0 & 100 \\
\hline Bahamas, The & 9 & 0 & 0 & 0 \\
\hline Bangladesh & 7 & 2 & 0.6 & 0 \\
\hline Belize & 8 & 0 & 0 & 0 \\
\hline Botswana & 7 & 4 & 0 & 57.6 \\
\hline Brunei Darussalam & 7 & 0 & 0 & 0 \\
\hline Cameroon & 3 & 2 & 2.9 & 0 \\
\hline Canada & 6 & 6 & 0 & 100 \\
\hline Cyprus & 9 & 0 & 0 & 0 \\
\hline Dominica & 9 & 0 & 0 & 0 \\
\hline Fiji & 7 & 4 & 0 & 47.7 \\
\hline Gambia, The & 5 & 0 & 0 & 0 \\
\hline Ghana & 8 & 3 & 0 & 10.3 \\
\hline Grenada & 8 & 0 & 0 & 0 \\
\hline Guyana & 4 & 0 & 0 & 0 \\
\hline India & 8 & 4 & 0 & 10 \\
\hline Jamaica & 8 & 0 & 0 & 0 \\
\hline Kenya & 10 & 4 & 0 & 3.3 \\
\hline Kiribati & 5 & 0 & 0 & 0 \\
\hline Lesotho & 6 & 0 & 0 & 0 \\
\hline Malawi & 7 & 0 & 0 & 0 \\
\hline Malaysia & 10 & 6 & 62 & 100 \\
\hline Maldives & 4 & 0 & 0 & 0 \\
\hline
\end{tabular}




\begin{tabular}{|c|c|c|c|c|}
\hline & $\begin{array}{l}\text { Strength of legal } \\
\text { rights index } \\
(0=\text { weak to } \\
10=\text { strong) }\end{array}$ & $\begin{array}{l}\text { Depth of credit } \\
\text { information } \\
\text { index }(0-6)^{18}\end{array}$ & 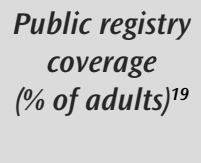 & $\begin{array}{c}\text { Private bureau } \\
\text { coverage } \\
(\% \text { of adults })^{20}\end{array}$ \\
\hline Mauritius & 5 & 3 & 49.8 & 0 \\
\hline Mozambique & 2 & 4 & 2.2 & 0 \\
\hline Namibia & 8 & 5 & 0 & 58.5 \\
\hline New Zealand & 10 & 5 & 0 & 100 \\
\hline Nigeria & 8 & 0 & 0 & 0 \\
\hline Pakistan & 6 & 4 & 5.8 & 1.4 \\
\hline Papua New Guinea & 5 & 3 & 0 & 0.6 \\
\hline Seychelles & 4 & 0 & 0 & 0 \\
\hline Sierra Leone & 6 & 0 & 0 & 0 \\
\hline Singapore & 10 & 4 & 0 & 60.8 \\
\hline Solomon Islands & 8 & 0 & 0 & 0 \\
\hline South Africa & 9 & 6 & 0 & 54.9 \\
\hline Sri Lanka & 4 & 5 & 0 & 18.6 \\
\hline St Kitts and Nevis & 7 & 0 & 0 & 0 \\
\hline St Lucia & 8 & 0 & 0 & 0 \\
\hline $\begin{array}{l}\text { St Vincent and the } \\
\text { Grenadines }\end{array}$ & 7 & 0 & 0 & 0 \\
\hline Swaziland & 6 & 5 & 0 & 35.7 \\
\hline Tonga & 7 & 0 & 0 & 0 \\
\hline Trinidad and Tobago & 8 & 4 & 0 & 45.2 \\
\hline Uganda & 7 & 4 & 0 & 1.1 \\
\hline United Kingdom & 9 & 6 & 0 & 100 \\
\hline United Republic of Tanzania & 8 & 0 & 0 & 0 \\
\hline Vanuatu & 9 & 0 & 0 & 0 \\
\hline Zambia & 9 & 5 & 0 & 3 \\
\hline
\end{tabular}

Source: World Bank Development Indicators 2011 